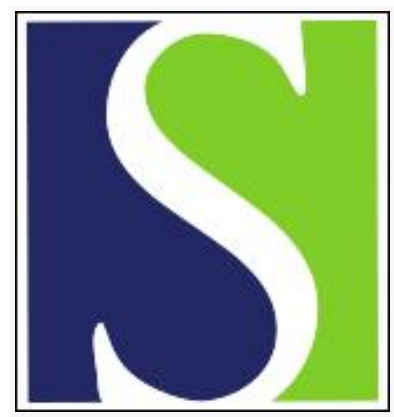

Scand J Work Environ Health 2013;39(4):343-350

https://doi.org/10.5271/sjweh.3345

Published online: 28 Jan 2013, Issue date: 01 Jul 2013

Disability pension due to musculoskeletal diagnoses: importance of work-related factors in a prospective cohort study of Finnish twins

by Kärkkäinen S, Pitkäniemi J, Silventoinen K, Svedberg $P$, Huunan-Seppälä A, Koskenvuo K, Koskenvuo M, Alexanderson K, Kaprio J, Ropponen A

Several work-related risk factors, such as physical workload and stress, are independent, direct risk factors for disability pension due to musculoskeletal diagnosis, not affected by familial factors. Identification of these risk factors during a person's lifespan would be beneficial for occupational health care and individuals to reduce permanent work incapacity due to musculoskeletal diagnosis.

Affiliation: Finnish Institute of Occupational Health, Topeliuksenkatu 41 a A, 00250 Helsinki, Finland. annina.ropponen@ttl.fi

Refers to the following text of the Journal: 2011;37(6):464-472

The following articles refer to this text: 2014;40(4):353-360;

2014;40(4):331-333

Key terms: disability pension; Finland; MSD; musculoskeletal diagnosis; musculoskeletal disorder; prospective cohort study; sick leave; sickness absence; twins; work; work-related factor

This article in PubMed: www.ncbi.nlm.nih.gov/pubmed/23359018

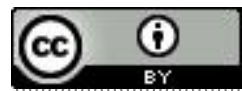




\title{
Disability pension due to musculoskeletal diagnoses: importance of work- related factors in a prospective cohort study of Finnish twins
}

\author{
by Sanna Kärkkäinen, MSc, ${ }^{1}$ Janne Pitkäniemi, PhD, ${ }^{2}$ Karri Silventoinen, PhD, 2, 3 Pia Svedberg, PhD, ${ }^{4}$ \\ Antti Huunan-Seppälä, MD, PhD, ${ }^{5}$ Karoliina Koskenvuo, ${ }^{6}$ PhD, Markku Koskenvuo, MD, ${ }^{2}$ PhD, Kristina \\ Alexanderson, PhD, ${ }^{4}$ Jaakko Kaprio, MD, 2, 7, 8 PhD, Annina Ropponen, PhD 9, 10
}

\begin{abstract}
Kärkkäinen S, Pitkäniemi J, Silventoinen K, Svedberg P, Huunan-Seppälä A, Koskenvuo K, Koskenvuo M, Alexanderson K, Kaprio J, Ropponen A. Disability pension due to musculoskeletal diagnoses: importance of workrelated factors in a prospective cohort study of Finnish twins. Scand J Work Environ Health. 2013;39(4):343-350. doi:10.5271/sjweh.3345
\end{abstract}

Objectives The aim of this study was to investigate the impact of work-related risk factors for future disability pension (DP) due to musculoskeletal diagnoses and for a subgroup of these, namely, DP due to osteoarthritis.

Methods For this prospective study of 16028 Finnish twins born in 1911-1957 and employed at baseline, a postal questionnaire collected information in 1975 on work-related factors; follow-up data on DP was gathered through register linkages up to 2004. A series of proportional hazards (Cox) regression models were used to analyze the associations between work-related factors and the incidence of DP.

Results During the 30-year follow-up, 1297 participants (8\%) were granted DP due to musculoskeletal diagnoses, 376 of which were due to osteoarthritis. High stress of daily activities, monotonous work, physical workload (namely work including lifting and carrying or physically heavy work), several workplace changes, and unemployment displayed a strong association with DP due to musculoskeletal diagnoses that was not affected by familial factors, including genetics and shared environment. Additionally, standing work increased the risk for DP due to osteoarthritis.

Conclusions Uninfluenced by family background or other confounding factors, several work-related factors were identified as being strong and direct risk factors for DP due to musculoskeletal diagnoses.

Key terms Finland; MSD; musculoskeletal disorder; sick leave; sickness absence; work.

Disability pension (DP) due to musculoskeletal diagnoses is a common cause for early exit from the labor market (1). In Finland, 24\% of DP in 2010 were attributable to musculoskeletal diagnoses, with the largest subgroups being osteoarthritis, low-back disorders, and rheumatoid arthritis (2). Similar patterns have been reported in other western countries (1). An earlier study of Finnish twins has shown that risk factors for DP due to musculoskeletal diagnoses, and specifically for osteoarthritis, may differ although being identifiable in the individual's lifespan (3).

Physical workload has been identified as a risk factor for musculoskeletal disorders (MSD) (4), osteoarthritis (5) and DP due to musculoskeletal diagnoses (6-8). There are also factors that may be indirectly related to work. For example, both work-related stress (9) and stress related to other aspects of life (10) seem to play a role in DP due to musculoskeletal diagnoses. Fur-

\footnotetext{
1 Public Health and Clinical Nutrition, School of Medicine, University of Eastern Finland, Kuopio, Finland.

2 Department of Public Health, Hjelt Institute, University of Helsinki, Helsinki, Finland.

3 Population Research Unit, Department of Social Research, University of Helsinki, Helsinki, Finland.

4 Division of Insurance Medicine, Department of Clinical Neuroscience, Karolinska Institutet, Stockholm, Sweden.

5 Department of General Practice, University of Tampere, Tampere, Finland.

6 Research Department, The Social Insurance Institution of Finland

7 Department of Mental Health and Substance Abuse Services, National Institute for Health and Welfare, Finland.

8 Institute of Molecular Medicine, University of Helsinki, Helsinki, Finland.

9 School of Medicine, University of Eastern Finland, Kuopio, Finland.

${ }^{10}$ Finnish Institute of Occupational Health, Helsinki, Finland
}

Correspondence to: Annina Ropponen, Finnish Institute of Occupational Health, Topeliuksenkatu 41 a A, 00250 Helsinki, Finland. [E-mail: annina.ropponen@ttl.fi] 
thermore, there appears to be an association between unemployment and DP due to rheumatoid arthritis (11).

In addition to these work-related factors, genetic factors and shared family environment contribute to the risk for DP $(12,13)$. These familial factors (that is both genetics and shared environment mainly in childhood) may therefore confound some observed epidemiological associations since these familial effects may influence the characteristics influencing DP due to musculoskeletal diagnoses. Until now, most previous studies have investigated work-related risk factors for chronic conditions, or if DP has been involved, with relatively short follow-up time $(3,6,14,15)$. However, studies with a life-course perspective would be needed if one wished to investigate work-related factors during life stages as identification of work-related risk factors would facilitate prevention of exposures and diagnoses leading to DP. This study investigates work-related factors as predictors for DP due to musculoskeletal diagnoses and separately for a subgroup of these, namely, DP due to osteoarthritis. In addition, we aimed to investigate the effect of familial factors (genetics and environmental factors shared by family members) in the associations between work-related factors and DP.

\section{Methods}

\section{Baseline data}

Data were obtained from the Finnish Twin Cohort Study (16). For this study, all individuals aged 18-64 years who were alive, resident in Finland, and not receiving a DP or old-age pension on 1 January 1975, and who had answered the postal questionnaire in 1975 (participation rate 89\%) were included $(\mathrm{N}=24043)$. Those not working at baseline (ie, reporting work status as home-makers, students, unemployed or others) were excluded ( $\mathrm{N}=8015)$. The final study sample included 16028 individuals, of whom 44\% were women. The number of complete twin pairs was 1870 monozygotic (MZ) and 3959 dizygotic (DZ) pairs. A questionnaire was used to determine zygosity (16).

With respect to work-related factors, data from the baseline questionnaire (www.twinstudy.helsinki.fi) included (i) perceived nature of work (monotonous versus variable); (ii) physical workload (described as work including mainly sitting, standing and walking, lifting and carrying, or being physically heavy labor: each participant could select only one category to describe his/ her work) (17); (iii) work types (day, evening, night, and shift work; in- or outdoor work or both); (iv) changes of workplace $(0,1-4, \geq 5$ times: the changes were accounted between workplaces due to any reason); (v) periods of unemployment $(0,1-4, \geq 5)$; (vi) duration of commuting including physical activity (walking, running, cycling, or skiing) to and from work $(<15,15-60, \geq 60$ minutes per day); (vii) provider of the family (no versus yes); (viii) and stress of daily activities (continuous variable). Stress was assessed using the Reeder Stress Inventory (18) and included four items: feelings of tension and nervousness, perceived stress, demands associated with daily activities, and daily mental and physical exhaustion. Each item was rated on a 4-point scale where the total stress score was 4-16, with a high score indicating low stress (19). For analytical purposes, the stress score (continuous) was reversed to facilitate interpretations. For descriptive purposes, the stress score was categorized into three classes: much (4-8 points), some (9-15 points), and little stress (16 points).

Sociodemographic factors included socioeconomic status and was based on self-reported occupation in 1975, including six categories: upper and lower white-collar workers, skilled and unskilled manual workers, farmers and others (those not identified elsewhere and at work at baseline) (20). Education was measured in nine categories of highest attained education and used as a continuous variable (years of education). Marital status was assessed as married (those living with a partner, including cohabitating, married, or re-married) versus single (unmarried living alone, including widowed or divorced).

Self-reported weight and height were used to calculate body mass index (BMI, $\mathrm{kg} / \mathrm{m}^{2}$ ). The validity of self-reported BMI has been found to be high (21). BMI was used in the analyses as a continuous variable.

\section{Follow-up data}

Information on the date of migration and death was obtained from regular updates from the Population Register of Finland. Information on pension events with diagnoses (the WHO International Classification of Diseases, ICD- $8^{\text {th }}, 9^{\text {th }}$ and $10^{\text {th }}$ revisions) during the follow-up period from 2 January 1975 to 31 December 2004 was obtained from the Social Insurance Institution and the Finnish Centre for Pensions. The unique personal identification code of all Finnish citizens was used for record linkage. All diagnoses, which originally included codes from classifications ICD-8, ICD-9, and ICD-10, were transformed to ICD-10 rubrics. The diagnoses included into this study were M00-M99 for DP due to musculoskeletal diagnoses and M05-M19 for DP due to osteoarthritis.

The granting of early retirement pension (DP or individual early retirement pension for 58-64-year old employees, which was in general abolished in 2005) requires a medically confirmed illness, disease, or injury that essentially restricts the capacity to work. No significant social or pension legislative changes concerning the disability criteria were established during the follow-up period of this study (22). 


\section{Statistical analysis}

First, in order to assess the association between baseline factors and DP due to musculoskeletal diagnoses, the Cox proportional hazards model was used to estimate hazard ratios (HR) with $95 \%$ confidence intervals $(95 \%$ CI) for each risk factor. Follow-up time was assessed as days from the baseline on 2 January 1975 until the date of awarding DP due to musculoskeletal diagnoses (cases), or to date of DP due to any other reason, emigration, or death (censored), or to the end of follow-up (non cases) on 31 December 2004, whichever came first. All analyses were adjusted for age. Clustering due to the twin pairing was taken into account in the statistical analysis using the cluster option to obtain robust standard errors that inflate the standard errors due to within pair correlation (23). Since there were no major differences between men and women based on the similarity of HR and overlapping CI, they were combined and all the analyses were adjusted for sex. The proportional hazards assumption was graphically tested by observing the "log-log" curves for the categories of risk factors and found not to be violated.

Second, the multivariable analyses were computed with all significant factors at $\mathrm{P}<0.05$ alpha level from analyses that were run separately for each variable. The multivariable model was additionally adjusted for: (i) education and socioeconomic status, (ii) marital status and (iii) BMI because these factors were found to be significant predictors for DP due to musculoskeletal diagnoses in an earlier study of this material and could potentially confound the associations between workrelated factors and DP (3).

Third, a conditional Cox proportional hazards model was applied in order to control for the effect of genetic and childhood environment including complete twin pairs discordant for DP due to musculoskeletal diagnoses (one twin was granted DP due to musculoskeletal diagnoses during the follow-up and the other twin was not granted DP for any reason). Conditional Cox proportional hazards models were conducted by analyzing the follow-up time to DP due to musculoskeletal diagnoses for one twin in relation to the follow-up time of the cotwin. The modeling was performed with stratification by twin pair allowing each twin pair their own baseline hazard. Moreover, the discordant pair analyses were performed separately for $\mathrm{MZ}$ and $\mathrm{DZ}$ pairs in order to estimate the possible role of familial effects [including both genetics and shared (childhood) environment such as social background] in the associations. Since MZ twins are genetically identical, the assumption can be tested that if common genetic factors play a role in the association of risk factors and the higher risk for DP, then the association should be seen within DZ but not $M Z$ twins. Hence, if the association exists within both $\mathrm{MZ}$ and DZ pairs, the role of environmental factors not related to the familial confounding can be presumed to be more influential. Since there were no systematic differences between $\mathrm{MZ}$ and $\mathrm{DZ}$ pairs based on the similarity of HR and overlapping CI, all the pairs were combined and analyzed together.

Fourth, all analyses were repeated for DP due to osteoarthritis as an outcome. The analyses were carried out with Stata statistical software, version 9.2 (Stata Corporation, College Station, TX, USA), and R version 2.9.0, packages used were survival, Epi, epicalc, and MASS distributed through the Comprehensive R Archive Network (cran.r-project.org).

\section{Ethics}

The Social Insurance Institution and the earnings-related pension institutes of Finland jointly granted permission to use the register data for this study through the TwinKela project. Only already existing epidemiological data were used. The Ethical Committee of the Department of Public Health at the University of Helsinki approved the study protocol. The twins in the Finnish Twin Cohort have been informed of the registry-based linkages in accordance with data protection legislation and guidance from the Data Protection Ombudsman.

\section{Results}

During the 30-year follow-up, 1297 (3\%) individuals (748 men and 549 women), who self-reported working at baseline in 1975, were granted DP due to musculoskeletal diagnoses and were on average 39.4 [standard deviation (SD) 9] years of age at baseline (table 1). Of these, 29\% had DP due to osteoarthritis (191 men and 185 women). The number of discordant twin pairs was $186 \mathrm{MZ}$ and $534 \mathrm{DZ}$ pairs for DP due to musculoskeletal diagnoses and $59 \mathrm{MZ}$ and $175 \mathrm{DZ}$ pairs for DP due to osteoarthritis. Mean follow-up time was 15.4 (SD 7) years for those granted DP due to musculoskeletal diagnoses and 22.7 (SD 9) years for the whole cohort.

In the age and sex-adjusted models, several factors showed significant association with higher risk of DP due to musculoskeletal diagnoses: (i) not being a provider of the family, (ii) high stress of daily activities, (iii) outdoor work and combined indoor and outdoor work compared to indoor work, (iv) shift work compared to day work, (v) work including lifting and carrying or described as physically heavy compared to sedentary work, (vi) changes of workplace ( $\geq 5$ versus 0 ), (vii) periods of unemployment ( $\geq 1$ versus 0 ), and (viii) monotonous work (table 2).

The additionally adjusted models were fitted to take into account the effect of work-related and sociode- 
Table 1. Baseline means (standard deviations) and percentages of baseline factors for those granted disability pension (DP) due to musculoskeletal disorder (MSD), those granted DP due to osteoarthritis (OA), those on DP due to other diagnoses than MSD, and those not on DP during follow-up and at work at baseline (1975). [BMI=body mass index; SD=standard deviation]

\begin{tabular}{|c|c|c|c|c|c|c|c|c|c|c|c|c|}
\hline \multirow[t]{2}{*}{ Baseline background factors } & \multicolumn{3}{|c|}{$\begin{array}{c}\text { DP due to MSD } \\
\text { including OA }(N=1297)\end{array}$} & \multicolumn{3}{|c|}{$\begin{array}{l}\text { DP due to OA } \\
(\mathrm{N}=367)\end{array}$} & \multicolumn{3}{|c|}{$\begin{array}{l}\text { DP due to other } \\
\text { reason }(N=2064)\end{array}$} & \multicolumn{3}{|c|}{$\begin{array}{c}\text { No DP } \\
(\mathrm{N}=12667)\end{array}$} \\
\hline & Mean & SD & $\%$ & Mean & SD & $\%$ & Mean & SD & $\%$ & Mean & SD & $\%$ \\
\hline Age (at the baseline 1975) & 39.4 & 9.3 & & 41.8 & 8.9 & & 36.9 & 10.1 & & 32.3 & 11.0 & \\
\hline Education (years) & 6.6 & 1.4 & & 6.5 & 1.3 & & 7.0 & 2.1 & & 7.8 & 2.7 & \\
\hline $\mathrm{BMI}\left(\mathrm{kg} / \mathrm{m}^{2}\right)$ & 24.7 & 3.3 & & 25.3 & 3.3 & & 24.3 & 3.4 & & 22.9 & 3.1 & \\
\hline Marital status (married) & & & 74 & & & 70 & & & 71 & & & 57 \\
\hline \multicolumn{13}{|l|}{ Socioeconomic status } \\
\hline Upper white-collar & & & 2 & & & 1 & & & 11 & & & 6 \\
\hline Lower white-collar & & & 21 & & & 27 & & & 23 & & & 45 \\
\hline Skilled worker & & & 46 & & & 43 & & & 47 & & & 38 \\
\hline Unskilled worker & & & 18 & & & 23 & & & 10 & & & 15 \\
\hline Farmer & & & 6 & & & 3 & & & 10 & & & 2 \\
\hline \multicolumn{13}{|l|}{ Risk factors } \\
\hline Provider of the family & & & 64 & & & 61 & & & 67 & & & 58 \\
\hline \multicolumn{13}{|c|}{ Stress of daily activities (range 4-16) } \\
\hline Little (16) & & & 18 & & & 19 & & & 17 & & & 20 \\
\hline Some (9-15) & & & 67 & & & 67 & & & 68 & & & 72 \\
\hline Much (4-8) & & & 15 & & & 14 & & & 15 & & & 7 \\
\hline \multicolumn{13}{|l|}{ Out- or indoor work } \\
\hline Indoor & & & 59 & & & 61 & & & 62 & & & 69 \\
\hline Outdoor & & & 14 & & & 15 & & & 14 & & & 11 \\
\hline Combined out- and indoor & & & 26 & & & 24 & & & 24 & & & 21 \\
\hline \multicolumn{13}{|c|}{ Physical work loading (type of work) } \\
\hline Sitting & & & 21 & & & 17 & & & 27 & & & 32 \\
\hline Standing & & & 15 & & & 19 & & & 19 & & & 18 \\
\hline Lifting and carrying & & & 49 & & & 50 & & & 42 & & & 41 \\
\hline Physically heavy & & & 14 & & & 14 & & & 12 & & & 8 \\
\hline \multicolumn{13}{|l|}{ Work type } \\
\hline Day & & & 81 & & & 80 & & & 82 & & & 82 \\
\hline Night & & & 1 & & & 1 & & & 1 & & & 1 \\
\hline Evening & & & 0 & & & 1 & & & 0 & & & 0 \\
\hline Shift work & & & 18 & & & 18 & & & 16 & & & 17 \\
\hline Nature of work monotonous & & & 26 & & & 23 & & & 23 & & & 21 \\
\hline \multicolumn{13}{|c|}{ Changes of workplace (number of times) } \\
\hline 0 & & & 13 & & & 11 & & & 15 & & & 19 \\
\hline $1-4$ & & & 51 & & & 52 & & & 53 & & & 58 \\
\hline$\geq 5$ & & & 35 & & & 37 & & & 32 & & & 23 \\
\hline \multicolumn{13}{|l|}{ Periods of unemployment } \\
\hline 0 & & & 67 & & & 67 & & & 66 & & & 75 \\
\hline $1-4$ & & & 26 & & & 26 & & & 27 & & & 22 \\
\hline$\geq 5$ & & & 7 & & & 8 & & & 7 & & & 3 \\
\hline \multicolumn{13}{|c|}{ Duration of commuting (minutes) } \\
\hline$<15$ & & & 54 & & & 55 & & & 53 & & & 54 \\
\hline $15-60$ & & & 39 & & & 38 & & & 41 & & & 40 \\
\hline$>60$ & & & 7 & & & 7 & & & 6 & & & 5 \\
\hline
\end{tabular}

mographic factors to each factor under study (table 2). Stress, monotonous work, lifting and carrying work, and changes of workplace were statistically significant risk factors for the outcome.

After accounting for familial confounding, by including only the discordant twin pairs, the factors with a strong association with DP were stress of daily activities, monotonous work, lifting and carrying work, physically heavy work, unemployment, and commuting $>15$ minutes by physical means (table 2 ).

\section{Disability pension due to osteoarthritis}

For DP due to osteoarthritis, most of the risk factors were similar to those identified for DP due to musculoskeletal diagnoses in the terms of magnitude and direction except for standing at work, which was a strong predictor for DP due to osteoarthritis (table 3 ) but not for DP due to musculoskeletal diagnoses (table 2). In the additionally adjusted model, significant risk factors for DP due to osteoarthritis were evening and monotonous work, standing at work, 
Table 2. Cox proportional hazard ratios (HR) with $95 \%$ confidence intervals $(95 \% \mathrm{Cl})$ of work-related factors for those granted disability pension (DP) due to musculoskeletal diagnoses ( $\mathrm{N}=1297)$ during follow up and at work at baseline (1975).

\begin{tabular}{|c|c|c|c|c|c|c|}
\hline & \multicolumn{2}{|c|}{ Age- and sex-adjusted } & \multicolumn{2}{|c|}{ Full model } & \multicolumn{2}{|c|}{ Discordant pairs } \\
\hline & $\mathrm{HR}$ & $95 \% \mathrm{Cl}$ & $H R^{a}$ & $95 \% \mathrm{Cl}$ & $\mathrm{HR}^{\mathrm{b}}$ & $95 \% \mathrm{Cl}$ \\
\hline Not provider of the family (versus yes) & 1.29 & $1.11-1.50$ & 1.17 & $0.97-1.41$ & 0.99 & $0.78-1.24$ \\
\hline Stress of daily activities & 1.06 & $1.04-1.09$ & 1.04 & $1.01-1.07$ & 1.06 & $1.03-1.10$ \\
\hline \multicolumn{7}{|l|}{ Out- or indoor work } \\
\hline Indoor & 1.00 & referent & 1.00 & referent & 1.00 & referent \\
\hline Outdoor & 1.33 & $1.11-1.60$ & 1.04 & $0.80-1.34$ & 1.04 & $0.79-1.38$ \\
\hline Combined out- and indoor & 1.35 & $1.17-1.55$ & 1.12 & $0.93-1.35$ & 0.86 & $0.70-1.07$ \\
\hline \multicolumn{7}{|l|}{ Work type } \\
\hline Day & 1.00 & referent & 1.00 & referent & 1.00 & referent \\
\hline Night & 0.86 & $0.44-1.65$ & 0.62 & $0.27-1.40$ & 0.58 & $0.23-1.44$ \\
\hline Evening & 1.39 & $0.50-3.85$ & 1.49 & $0.59-3.75$ & - & . \\
\hline Shift work & 1.24 & $1.07-1.44$ & 1.09 & $0.90-1.31$ & 1.17 & $0.93-1.46$ \\
\hline Nature of work monotonous (versus variable) & 1.62 & $1.42-1.85$ & 1.53 & $1.29-1.81$ & 1.37 & $1.10-1.70$ \\
\hline \multicolumn{7}{|l|}{ Physical work loading (type of work) } \\
\hline Sitting & 1.00 & referent & 1.00 & referent & 1.00 & referent \\
\hline Standing & 1.19 & $0.99-1.43$ & 1.06 & $0.85-1.33$ & 0.93 & $0.70-1.22$ \\
\hline Lifting and carrying & 1.83 & $1.58-2.12$ & 1.52 & $1.24-1.85$ & 1.40 & $1.11-1.76$ \\
\hline Physically heavy & 2.08 & $1.70-2.54$ & 1.27 & $0.94-1.72$ & 1.37 & $1.00-1.88$ \\
\hline \multicolumn{7}{|l|}{ Changes of workplace (number of times) } \\
\hline 0 & 1.00 & referent & 1.00 & referent & 1.00 & referent \\
\hline $1-4$ & 1.17 & $0.98-1.39$ & 1.43 & $1.13-1.81$ & 1.04 & $0.81-1.34$ \\
\hline$\geq 5$ & 1.59 & $1.32-1.91$ & 1.72 & $1.35-2.21$ & 1.31 & $0.98-1.76$ \\
\hline \multicolumn{7}{|l|}{ Periods of unemployment } \\
\hline 0 & 1.00 & referent & 1.00 & referent & 1.00 & referent \\
\hline $1-4$ & 1.38 & $1.19-1.59$ & 1.13 & $0.94-1.35$ & 1.58 & $1.26-1.98$ \\
\hline$\geq 5$ & 1.79 & $1.50-2.14$ & 1.20 & $0.95-1.52$ & 1.42 & $1.04-1.95$ \\
\hline \multicolumn{7}{|l|}{ Duration of commuting (minutes) } \\
\hline$<15$ & 1.00 & referent & & & 1.00 & referent \\
\hline $15-60$ & 1.04 & $0.92-1.17$ & & & 1.46 & $1.20-1.77$ \\
\hline$>60$ & 1.14 & $0.91-1.44$ & & & 1.50 & $1.04-2.17$ \\
\hline
\end{tabular}

a The full model is additionally adjusted for BMI, education and socioeconomic and marital status.

${ }^{\mathrm{b}}$ Conditional Cox proportional hazard (within pair, number of discordant pairs: $\mathrm{MZ}=186$ pairs and $\mathrm{DZ}=534$ pairs).

lifting and carrying at work, several workplace changes, and unemployment. In discordant twin-pair analysis accounting for familial effects (table 3), standing at work, lifting and carrying at work, unemployment, and changes of workplace were statistically significant for such DP.

\section{Discussion}

This study aimed to investigate work-related factors as predictors for DP due to musculoskeletal diagnoses and DP due to osteoarthritis in a cohort of 16028 adults who were in employment at baseline in 1975 and followed for three decades. Many factors reflecting different aspects of work confirmed findings in the literature (6-8). The results suggest that several work-related factors are potentially associated with permanent work incapacity and furthermore, these factors can be identified during the individual's lifespan.
The independent effect of work on the risk for DP due to musculoskeletal diagnoses was tested through multivariable models and the use of discordant twin pairs. Multivariable models provide statistical evidence for the independent contribution of a risk factor even when known confounders are taken into account. The twin model provides additional evidence by demonstrating that the association also holds within families, providing adjustment for shared environmental as well as genetic factors. Thus, one may argue that such a finding is strong evidence for a true, possibly direct association. This unique opportunity of using two designs within the same study revealed that many risk factors had such strong associations. For DP due to musculoskeletal diagnoses, high stress of daily activities, monotonous work, and lifting and carrying at work are thus expected to have a direct effect on the susceptibility to DP (ie, being independent from familial effects). For DP due to osteoarthritis, such factors are standing or lifting and carrying at work, workplace changes, and unemployment. 
Table 3. Cox proportional hazard ratios (HR) with $95 \%$ confidence intervals $(95 \% \mathrm{Cl})$ of work-related factors for those granted disability pension (DP) due to osteoarthritis $(\mathrm{N}=376)$ during follow up and reporting to be at work at baseline (1975). [na=not possible to assess due to low number of discordant twin pairs]

\begin{tabular}{|c|c|c|c|c|c|c|}
\hline & \multicolumn{2}{|c|}{ Age- and sex-adjusted } & \multicolumn{2}{|c|}{ Full model a } & \multicolumn{2}{|c|}{ Discordant pairs $^{b}$} \\
\hline & $\mathrm{HR}$ & $95 \% \mathrm{Cl}$ & $\mathrm{HR}$ & $95 \% \mathrm{Cl}$ & $\mathrm{HR}$ & $95 \% \mathrm{Cl}$ \\
\hline Not provider of the family (versus yes) & 1.37 & $1.06-1.78$ & 1.32 & $0.93-1.86$ & 0.85 & $0.57-1.26$ \\
\hline Stress of daily activities & 1.05 & $1.01-1.10$ & 1.01 & $0.97-1.06$ & 1.04 & $0.98-1.11$ \\
\hline \multicolumn{7}{|l|}{ Out- or indoor work } \\
\hline Indoor & 1.00 & referent & 1.00 & referent & 1.00 & referent \\
\hline Outdoor & 1.47 & $1.05-2.06$ & 1.01 & $0.61-1.66$ & 1.05 & $0.62-1.78$ \\
\hline Combined out- and indoor & 1.33 & $1.03-1.72$ & 1.03 & $0.71-1.47$ & 1.10 & $0.72-1.69$ \\
\hline \multicolumn{7}{|l|}{ Work type } \\
\hline Day & 1.00 & referent & 1.00 & referent & 1.00 & referent \\
\hline Night & 0.64 & $0.16-2.61$ & 0.74 & $0.17-3.18$ & 1.00 & $0.14-7.10$ \\
\hline Evening & 3.11 & $0.95-10.16$ & 3.61 & $1.21-10.76$ & na & - \\
\hline Shift work & 1.32 & $1.01-1.72$ & 1.17 & $0.83,1.65$ & 1.37 & $0.90-2.07$ \\
\hline Nature of work monotonous (versus variable) & 1.34 & $1.04-1.72$ & 1.41 & $1.04,1.92$ & 1.00 & $0.65-1.53$ \\
\hline \multicolumn{7}{|l|}{ Physical work loading (type of work) } \\
\hline Sitting & 1.00 & referent & 1.00 & referent & 1.00 & referent \\
\hline Standing & 1.83 & $1.31-2.56$ & 1.60 & $1.05-2.43$ & 1.81 & $1.05-3.10$ \\
\hline Lifting and carrying & 2.31 & $1.74-3.07$ & 2.11 & $1.40-3.17$ & 1.91 & $1.18-3.10$ \\
\hline Physically heavy & 2.38 & $1.61-3.50$ & 1.52 & $0.79-2.92$ & 1.84 & $0.90-3.80$ \\
\hline \multicolumn{7}{|l|}{ Changes of workplace (number of times) } \\
\hline 0 & 1.00 & referent & 1.00 & referent & 1.00 & referent \\
\hline $1-4$ & 1.41 & $0.99-2.01$ & 1.58 & $0.98-2.55$ & 1.51 & $0.90-2.55$ \\
\hline$\geq 5$ & 1.95 & $1.36-2.81$ & 1.95 & $1.16-3.26$ & 2.40 & $1.28-4.49$ \\
\hline \multicolumn{7}{|l|}{ Periods of unemployment } \\
\hline 0 & 1.00 & referent & 1.00 & referent & 1.00 & referent \\
\hline $1-4$ & 1.59 & $1.22-2.06$ & 1.44 & $1.03-2.01$ & 2.32 & $1.46-3.68$ \\
\hline$\geq 5$ & 1.86 & $1.33-2.60$ & 1.10 & $0.68-1.79$ & 1.52 & $0.86-2.66$ \\
\hline \multicolumn{7}{|l|}{ Duration of commuting (minutes) } \\
\hline$<15$ & 1.00 & referent & & & 1.00 & referent \\
\hline $15-60$ & 0.93 & $0.73-1.17$ & & & 0.89 & $0.61-1.30$ \\
\hline$>60$ & 1.08 & $0.72-1.64$ & & & 1.58 & $0.74-3.37$ \\
\hline
\end{tabular}

a The full model is additionally adjusted for BMI, education and socioeconomic and marital status.

${ }^{\mathrm{b}}$ Conditional Cox proportional hazard (within pair, number of discordant pairs: $\mathrm{MZ}=59$ pairs and $\mathrm{DZ}=175$ pairs).

Some work-related factors were clearly independent of familial effects, and the rest of the associations between DP and work-related factors, such as shift and outdoor work, were of a similar direction and magnitude in the discordant-pair analyses pointing to independence from familial effects. This novel finding, although based on a limited number of discordant twin pairs and therefore not being directly tested, needs to be assessed cautiously. Further studies with even larger sample sizes or pooling together different data sets would be needed to confirm these findings and their applicability to other populations. Furthermore, our results with 30 years of follow-up time suggest that identification of persons at risk for DP may be of interest for occupational healthcare.

Physical workload was a risk factor for both DP due to musculoskeletal diagnoses and osteoarthritis. These findings are in line with a study showing that an unfavorable ergonomic situation (such as heavy lifting) increased the risk of DP (7), but also agree with studies showing increased risk with physical workload for DP due to musculoskeletal diagnoses (8) and DP due to osteoarthritis (24). In an attempt to further clarify the role of work-related factors for DP, we used socioeconomic status and education as confounders in the models. This analytic strategy was selected to account for different aspects of socioeconomic and occupational prerequisites to obtain as conservative estimates as possible for work-related factors, since socioeconomic status and education both play roles in musculoskeletal diagnoses (25) and DP due to musculoskeletal diagnoses $(3,8)$ and work-related factors $(26,27)$.

Secondary to work - but important when one considers work capacity - is the finding that stress influences the risk of DP due to musculoskeletal diagnoses and osteoarthritis. The subjective measure of stress used in this study may be related to excess workload or it may reflect a way to react to stressful life events. In this study, stress was an independent risk factor for DP due to musculoskeletal diagnoses and osteoarthritis. This effect of stress for future DP due to musculoskeletal diagnoses adds to the rather scarce prior knowledge on the association between stress and future DP $(9,10)$. 
Periods of unemployment and changes of workplace were associated with a higher risk for DP due to musculoskeletal diagnoses and osteoarthritis, possibly reflecting the socioeconomic situation or demographic fluctuations. In previous studies, unemployment has been a predictor for higher risk of DP due to rheumatoid arthritis (11), DP due to low-back diagnoses (15), and limited work capacity (28), but no such association was found for short-term unemployment and DP due to musculoskeletal diagnoses (29). Our finding is pronounced as we used the selection criterion of being at work at baseline and despite the fact that criterion changes of workplace and unemployment prior to baseline in 1975 were significant factors for future DP.

There are only a few prospective population-based cohort studies which have examined the work-related determinants of DP due to musculoskeletal diagnoses or osteoarthritis using long ( $>10$ years) follow-up times. In these studies, both physical and psychological workload have been shown to be risk factors for DP due to musculoskeletal diagnoses (6-8). Our results with 30 years of follow-up confirm and extend these findings and demonstrate that work-related risk factors can be identified in the working life. As these work-related factors, common in many workplaces, were collected through a questionnaire, they could be assumed to provide means for identification of those persons at risk. These individuals could be subjected to more detailed evaluation of work capacity in an attempt to prevent work disability and early retirement. Hence, the identified work-related factors would be potential targets for health promotion through individual, organizational, or societal interventions.

The study strengths include the large populationbased cohort including both sexes, the prospective study design with a long follow-up time, and the high quality registry data, including dates and diagnosis for DP with follow-up for all individuals. The cohort was not restricted to one occupation or socioeconomic group and is well comparable to the general Finnish working age population (16). Moreover, the use of a twin setting allowed adjustment for familial factors and thus offers an additional assessment of causality. Limitations include the self-reported comprehensive work-related data possibly affected by recall bias. In addition, workrelated factors can be interrelated and, hence, teasing out their effects from each other can be very difficult. Another limitation is the drop-out due to non-response. However, this was small as the response rate at baseline was high. A further limitation of this study can be that any changes that might have occurred in the studied work-related risk factors or musculoskeletal symptoms and other morbidity in the follow-up period may have weakened the observed associations. This cannot be ruled out in this study hence further studies are needed to elaborate the relationship between stability or change in workloading and development of chronic conditions. Furthermore, we included several background factors into our full model, and one can question whether our results are in fact over adjusted. However, the associations only slightly attenuated due to these adjustments, and thus our results show the lowest level of the effect size when the real effect size is likely to be stronger.

\section{Concluding remarks}

Many work-related factors are potentially associated with permanent work incapacity. Physical workloading, stress of daily activities, changes of workplace, and unemployment appear to be strong and direct risk factors for DP due to musculoskeletal diagnoses independent from various mediating factors including familial effects.

\section{Acknowledgments}

The Social Insurance Institute, Finland supports the TwinKela project. The Academy of Finland Centre of Excellence in Complex Disease Genetics supports the Finnish Twin Cohort studies (grant numbers: 213506, 129680). A Ropponen is supported by an Academy of Finland researcher grant (\# 122080) and the Finnish Work Environment Fund. P Svedberg and K Alexanderson are supported by grants from the Swedish Council for Working Life and Social Research (including the Stockholm Stress Center), and Karolinska Institutet Centre for Healthcare Science.

\section{References}

1. Bevan S, Quadrello T, McGee R, Mahdon M, Vavrovsky A, Barham L. Fit For Work? Musculoskeletal Disorders in the European Workforce. London: The Work Foundation; 2009.

2. Statistical yearbook of the Social Insurance Institution 2010 Official Statistics of Finland. 2011.

3. Ropponen A, Silventoinen K, Svedberg P, Alexanderson K, Koskenvuo K, Huunan-Seppälä A, et al. Health-related risk factors for disability pensions due to musculoskeletal diagnoses: A 30-year Finnish twin cohort study. Scand J Public Health. 2011;39:839-48. http://dx.doi.org/10.1177/1403494811418283.

4. Punnett L, Wegman DH. Work-related musculoskeletal disorders: the epidemiologic evidence and the depate. J Electromyogr Kinesiol. 2004;14:13-23. http://dx.doi. org/10.1016/j.jelekin.2003.09.015.

5. Juhakoski R, Heliövaara M, Impivaara $\mathrm{O}$, Kröger $\mathrm{H}$, Knekt $\mathrm{P}$, Lauren $\mathrm{H}$, et al. Risk factors for the development of hip osteoarthritis: a population-based prospective study. Rheumatol. 2009;48:83-7. http://dx.doi.org/10.1093/rheumatology/ken427. 
6. Karpansalo M, Manninen P, Lakka TA, Kauhanen J, Rauramaa R, Salonen JT. Physical Workload and Risk of Early Retirement: Prospective Population-Based Study Among Middle-Aged Men. J Occup Environ Med. 2002;44:930-9. http://dx.doi.org/10.1097/00043764-200210000-00012.

7. Stattin M, Jarvholm B. Occupation, work environment, and disability pension: a prospective study of construction workers. Scand J Public Health. 2005;33:84-90. http://dx.doi. org/10.1080/14034940410019208.

8. Leinonen T, Pietilainen $\mathrm{O}$, Laaksonen $\mathrm{M}$, Rahkonen $\mathrm{O}$, Lahelma E, Martikainen P. Occupational social class and disability retirement among municipal employees--the contribution of health behaviors and working conditions. Scand J Work Environ Health. 2011;37:464-72. http://dx.doi. org/10.5271/sjweh.3182.

9. Ahola K, Gould R, Virtanen M, Honkonen T, Aromaa A, Lönnqvist J. Occupational burnout as a predictor of disability pension: a population-based cohort study. Occup Environ Med. 2009;66:284-90. http://dx.doi.org/10.1136/ oem.2008.038935

10. Kaiser PO, Mattsson B, Marklund S, Wimo A. Health and disability pension--an intersection of disease, psychosocial stress and gender. Long term follow up of persons with impairment of the locomotor system. Work. 2008;31:209-19.

11. Holte HH, Tambs K, Bjerkedal T. Becoming a disability pensioner with rheumatoid arthritis in Norway 1971-1990. J Rheumatol. 2001;28:54-61.

12. Harkonmäki K, Silventoinen K, Levälahti E, Pitkäniemi J, Huunan-Seppälä A, Klaukka T, et al. The Genetic Liability to Disability Retirement: A 30-Year Follow-Up Study of 24,000 Finnish Twins. PLoS ONE. 2008;3:e3402. http://dx.doi. org/10.1371/journal.pone.0003402.

13. Narusyte J, Ropponen A, Silventoinen K, Alexanderson K, Kaprio J, Samuelsson $\AA$, et al. Genetic Liability to Disability Pension in Women and Men: A Prospective Population-Based Twin Study. PLoS ONE. 2011;6:e23143. http://dx.doi. org/10.1371/journal.pone.0023143.

14. Ropponen A, Narusyte J, Alexanderson K, Svedberg P. Stability and change in health behaviours as predictors for disability pension: a prospective cohort study of Swedish twins. BMC Public Health. 2011;11:68. http://dx.doi. org/10.1186/1471-2458-11-678.

15. Ropponen A, Silventoinen K, Svedberg P, Alexanderson K, Huunan-Seppala A, Koskenvuo K, et al. Effects of Work and Lifestyle on Risk for Future Disability Pension Due to Low Back Diagnoses: A 30-Year Prospective Study of Finnish Twins. J Occup Environ Med. 2012;54:1330-6. http://dx.doi. org/10.1097/JOM.0b013e3182775881.

16. Kaprio J, Koskenvuo M. Genetic and environmental factors in complex diseases: the older Finnish twin cohort. Twin Research. 2002;5:358-65.

17. Kaprio J, Kujala UM, Koskenvuo M, Sarna S. Physical activity and other risk factors in male twin-pairs discordant for coronary heart disease. Atherosclerosis. 2000;150:193-200. http://dx.doi.org/10.1016/S0021-9150(99)00368-8.
18. Reeder LG, Chapman JM, Coulson AH. Socioenvironmental stress, tranquilizers and cardiovascular disease. Proc Excerpta Medica Int Congr Ser. 1968;182:226-38.

19. Lillberg K, Verkasalo PK, Kaprio J, Teppo L, Helenius $\mathrm{H}$, Koskenvuo M. Stress of daily activities and risk of breast cancer: A prospective cohort study in Finland. Int J Cancer 2001;91:888-93. http://dx.doi.org/10.1002/10970215(200002)9999:9999<::AID-IJC1138>3.0.CO;2-D.

20. Kaprio J, Sarna S, Fogelholm M, Koskenvuo M. Total and occupationally active life expectancies in relation to social class and marital status in men classified as healthy at 20 in Finland. J Epidemiol Community Health. 1996;50:653-60. http://dx.doi.org/10.1136/jech.50.6.653.

21. Korkeila M, Kaprio J, Rissanen A, Koskenvuo M, Sörensen TI. Predictors of major weight gain in adult Finns: stress, life satisfaction and personality traits. Int $\mathrm{J}$ Obes Relat Metab Disord. 1998;22:949-57. http://dx.doi.org/10.1038/ sj.ijo.0800694.

22. Hietaniemi M, Vidlund M. The Finnish Pension System. Helsinki: Finnish Centre for Pensions; 2003.

23. Williams RL. A note on robust variance estimation for clustercorrelated data. Biometrics. 2000;56:645-6. http://dx.doi. org/10.1111/j.0006-341X.2000.00645.x.

24. Holte HH, Tambs K, Bjerkedal T. Manual work as predictor for disability pensioning with osteoarthritis among the employed in Norway 1971-1990. Int J Epidemiol. 2000;29:487-94. http://dx.doi.org/10.1093/ije/29.3.487.

25. Aluoch MA, Wao HO. Risk factors for occupational osteoarthritis: a literature review. AAOHN J. 2009;57:283-90. http://dx.doi.org/10.3928/08910162-20090625-10.

26. Bauer GF, Huber CA, Jenny GJ, Muller F, Hammig O Socioeconomic status, working conditions and self-rated health in Switzerland: explaining the gradient in men and women. Int J Public Health. 2009;54:23-30. http://dx.doi. org/10.1007/s00038-008-7077-2.

27. Johansson E, Leijon O, Falkstedt D, Farah A, Hemmingsson T. Educational differences in disability pension among Swedish middle-aged men: role of factors in late adolescence and work characteristics in adulthood. J Epidemiol Community Health. 2012;66:901-7. http://dx.doi.org/10.1136/jech-2011200317.

28. Rueda S, Chambers L, Wilson M, Mustard C, Rourke SB, Bayoumi A, et al. Association of returning to work with better health in working-aged adults: a systematic review. Am J Public Health. 2012;102:541-56. http://dx.doi.org/10.2105/ AJPH.2011.300401.

29. Gjesdal S, Ringdal PR, Haug K, Maeland JG. Predictors of disability pension in long-term sickness absence: Results from a population-based and prospective study in Norway 1994 1999. Eur J Public Health. 2004;14:398-405. http://dx.doi. org/10.1093/eurpub/14.4.398.

Received for publication: 23 May 2012 